\title{
Life cycle of midlatitude deep convective systems in a Lagrangian framework
}

\author{
Zhe Feng, ${ }^{1,2}$ Xiquan Dong, ${ }^{1}$ Baike Xi, ${ }^{1}$ Sally A. McFarlane, ${ }^{2}$ Aaron Kennedy, ${ }^{1}$ Bing Lin, ${ }^{3}$ \\ and Patrick Minnis ${ }^{3}$ \\ Received 29 June 2012; revised 12 October 2012; accepted 15 October 2012; published 1 December 2012.
}

[1] Deep convective systems (DCSs) consist of intense convective cores (CC), large stratiform rain (SR) regions, and extensive nonprecipitating anvil clouds (AC). This study focuses on the evolution of these three components and the factors that affect system lifetime and AC production. An automated satellite tracking method is used in conjunction with a recently developed multisensor hybrid classification to analyze the evolution of DCS structure in a Lagrangian framework over the central United States. Composite analysis from 4221 tracked DCSs during two warm seasons (May-August, 2010-2011) shows that maximum system size correlates with lifetime, and longer-lived DCSs have more extensive SR and AC. For short to medium systems (lifetimes $<6 \mathrm{~h}$ ), the lifetime is mainly attributed to the intensity of the initial convection. Systems that last longer than $6 \mathrm{~h}$ are associated with up to $50 \%$ higher midtropospheric relative humidity and up to $40 \%$ stronger middle to upper tropospheric wind shear. Such environments allow continuous growth of detrained hydrometeors by deposition, supporting further development of the SR and AC region, as indicated by the increased staggered timing between stratiform clouds and peak convective intensity, thus prolonging the system lifetime beyond $6 \mathrm{~h}$. Regression analysis shows that the areal coverage of thick AC is strongly correlated with the size of CC, updraft strength, and SR area. Ambient upper tropospheric wind speed and wind shear also play an important role for convective AC production, where for systems with large AC (radius $>120 \mathrm{~km}$ ) they are $24 \%$ and $20 \%$ higher, respectively, than those with small AC (radius $=20 \mathrm{~km}$ ).

Citation: Feng, Z., X. Dong, B. Xi, S. A. McFarlane, A. Kennedy, B. Lin, and P. Minnis (2012), Life cycle of midlatitude deep convective systems in a Lagrangian framework, J. Geophys. Res., 117, D23201, doi:10.1029/2012JD018362.

\section{Introduction}

[2] A deep convective system (DCS) is a contiguous high cloud shield that consists of active deep convective cores and cirrus anvil canopy. The convective cores produce heavy precipitation and provide moisture to the upper troposphere to maintain the DCS stratiform precipitation and the nonprecipitating anvil cloud [Lin et al., 2007]. The anvil cloud shields dominate the DCS radiative budget due to their large spatial coverage.

[3] Because they cover large areas, satellite observations are needed to examine the radiative impact of DCSs and to study the life cycle of convective clusters [Machado and Rossow, 1993; Del Genio and Kovari, 2002; Feng et al.,

\footnotetext{
${ }^{1}$ Department of Atmospheric Sciences, University of North Dakota, Grand Forks, North Dakota, USA.

${ }^{2}$ Pacific Northwest National Laboratory, Richland, Washington, USA.

${ }^{3}$ NASA Langley Research Center, Hampton, Virginia, USA.

Corresponding author: Z. Feng, Pacific Northwest National Laboratory, PO Box 999, MS K9-24, Richland, WA 99352, USA. (zhe.feng@pnnl.gov)

This paper is not subject to U.S. copyright.

Published in 2012 by the American Geophysical Union.
}

2011]. Williams and Houze [1987] developed an objective tracking technique using geostationary satellite data to study the cloud clusters over the western Pacific maritime continent during the Winter Monsoon Experiment. Pope et al. [2008] used multiyear Japanese Meteorological Agency Geostationary Meteorological Satellite-5 Infrared (IR) data to track and study the evolution of Mesoscale Convective Systems (MCSs) over northern Australia and surrounding oceans. They found that the minimum brightness temperatures of MCSs decreased slowly as their sizes reached maximum values during their mature stage, suggesting that the areal growth during that stage results from anvil formation, although they could not determine the amount of cirrus anvils by using IR data alone. Futyan and Del Genio [2007] used geostationary Meteosat- 8 satellite data to identify and track organized convective systems over tropical African and Atlantic regions, and subsequently matched these satellite data with overpasses from the Tropical Rainfall Measurement Mission (TRMM) satellite and composited vertical structure based upon their related life cycle stages. They found that African storms are convectively active with frequent lightning during their developing stages and evolve into more stratiform structures as they dissipate. In general, 
intense storms have larger cloud sizes, greater thicknesses, and longer durations than weak storms. They hypothesized that convective intensity might be a useful statistical predictor for use in generation circulation models (GCMs) to simulate the eventual sizes of DCSs without resolving mesoscale dynamics.

[4] In the midlatitude, particularly in the United States, DCSs occurring in the warm season (May-August) are often associated with a wide variety of severe weather events and significant precipitation. Maddox [1980] first noted a particular type of long-lasting MCS, termed Mesoscale Convective Complex (MCC) that frequently occurs over the central United States, grows to tremendous areal extent and often persists over $12 \mathrm{~h}$. Composite analysis of satellite IR and surface precipitation data by McAnelly and Cotton [1989] showed that average rainfall intensity peaks early in the satellite IR-defined life cycle, similar to the results shown by Kane et al. [1987]. Jirak et al. [2003] compared several types of MCSs using satellite and radar data during the warm seasons and found that elongated MCSs are most common, and are most likely associated with severe weather and the most intense precipitation. In additional to their impact on society through severe weather, these systems also modulate the climate system through their impacts on the water cycle and cloud radiative forcing and feedback. Despite their importance, most GCMs do not correctly simulate the diurnal cycle of warm season continental precipitation [Dai, 2006], in part due to the absence of mesoscale organization that generates extensive stratiform rain, preventing the lifetime of DCSs from extending beyond the decay time of individual convective events [Del Genio et al., 2012]. This error could have significant impact on the cloud radiative feedback associated with DCSs in GCMs. Feng et al. [2011] found that stratiform rain and anvil clouds from DCSs in the southern great plains of the United States have peak areal coverage from late evening to early morning, and that anvil clouds are major contributors to the summertime TOA radiative budget. Errors in the timing and extent of DCS stratiform rain and anvil clouds may result in incorrect diurnal forcing due to erroneous cloud radiative feedbacks.

[5] This study focuses on the DCS cloud life cycle in the central United States, particularly on the evolution from convective to stratiform anvil cloud structures, and the factors controlling convective anvil production. Previous studies of DCSs over various tropical land locations found many similarities in terms of cloud life cycles [Machado et al., 1998; Machado and Laurent, 2004; Kondo et al., 2006; Futyan and Del Genio, 2007; Pope et al., 2008]. If these characteristics hold true for midlatitudes as well, such "universal" behavior would provide useful insights and implications for parameterization development in future GCMs. The large spatial coverage of the Next-Generation Radar (NEXRAD) network and routinely available Geostationary Operational Environmental Satellite (GOES) data over the continental U.S. are valuable observational resources for studying the DCS life cycle in the midlatitudes. By implementing a satellite cloud tracking method along with the hybrid classification developed by Feng et al. [2011], the evolution of the major DCS components is analyzed here in a Lagrangian framework to study the morphology of midlatitude DCS clouds. Section 2 describes the data sets and methodology used in this study; section 3 discusses the evolution of DCS structures. Section 4 investigates factors that affect anvil production, and finally, a summary and concluding remarks are given in section 5 .

\section{Data and Methodology}

[6] The data sets used in this study are similar to those in Feng et al., [2011]: both NEXRAD radar and GOES satellite observations over the central United States $\left(25-40^{\circ} \mathrm{N}, 80\right.$ $105^{\circ} \mathrm{W}$ ) during two warm seasons (May-August) in 2010 and 2011. However, the focus of this study is on the DCS life cycle, while the previous one was on the TOA radiation budget.

[7] The NEXRAD data were obtained from the National Mosaic and Multisensor Quantitative Precipitation Estimate (QPE) system (NMQ) [Zhang et al., 2011]. Reflectivity data from all NEXRAD radars in the contiguous United States were quality controlled and objectively projected onto a unified three-dimensional Cartesian grid. Instantaneous rain rate data provided in the QPE product are derived using Z-R relationships for convective, stratiform and tropical rain types. The NMQ three-dimensional Mosaic reflectivity data set has a fixed $0.01^{\circ}(\sim 1 \mathrm{~km})$ horizontal resolution, a $0.5 \mathrm{~km}$ vertical resolution up to $18 \mathrm{~km}$ above mean sea level, and 5 min temporal resolution. The GOES cloud products are retrieved using the algorithms developed for the NASA Clouds and Earth's Radiant Energy System (CERES) project [Minnis et al., 2008, 2011]. The GOES cloud properties used in this study are $10.8 \mu \mathrm{m}$ channel brightness temperature $\left(T_{I R}\right)$, and cloud top and cloud base heights with a pixel resolution of about $4.5 \times 10 \mathrm{~km}$ and temporal resolution of $30 \mathrm{~min}$.

[8] The three-dimensional temperature, moisture, and wind fields used in this study were obtained from the National Centers for Environmental Prediction (NCEP) North America Regional Reanalysis (NARR) [Mesinger et al., 2006]. The NCEP NARR data set has $3 \mathrm{~h}$ temporal, $32 \mathrm{~km}$ horizontal, and 45-layer vertical resolutions over the North American domain. NARR uses the operational NCEP Eta Model and its three-dimensional variational data assimilation technique to improve on NCEP reanalysis by accurately assimilating precipitation [Kennedy et al., 2011]. The use of the NARR data set is intended to investigate largescale circulation and moisture variations associated with DCS development, rather than resolving convective-scale features (e.g., updraft velocity) due to its spatial and temporal resolution.

[9] The multisensor hybrid classification technique developed by Feng et al. [2011] is applied to the matched NEXRAD and GOES data sets. This technique jointly analyzes the collocated three-dimensional NEXRAD reflectivity structure and GOES $\mathrm{T}_{\mathrm{IR}}$ fields to objectively identify DCSs and to subsequently classify convective core (CC), stratiform rain (SR) and anvil cloud (AC) components from DCSs. Compared to previous studies that use only satellite $\mathrm{T}_{\mathrm{IR}}$ thresholds to define DCS and separate convective core and anvil clouds, the hybrid classification method avoids misidentification of nonconvective cold cirrus clouds as DCS, and explicitly separates SR, thick and thin nonraining ACs from CC. This is particularly suited for investigating their life cycles because the dynamical and microphysical properties are distinctly different between these regions. The 
$1 \mathrm{~km}$ resolution NEXRAD radar data are convolved into the GOES pixels as described by Feng et al. [2011].

[10] To obtain the environment where DCSs form, the 3 -hourly NARR data set is used at the time when it is available and collocated with DCSs identified by the hybrid classification. For example, if a DCS initiates at 00 UTC and dissipates at 08 UTC within the study domain, the environmental condition for this DCS is then obtained from NARR at 00,03 and 06 UTC. While NARR is not available at each hourly time step of all the DCSs, by compositing large data samples the overall environmental condition associated with DCSs of a given lifetime or AC area can be obtained. The time-matched and collocated NARR wind and moisture profiles are averaged within individual DCSs and saved for further analysis.

[11] An automated satellite tracking method is developed to study the life cycles of DCSs by tracking the evolution of the systems and subsequently incorporating with the corresponding classification of $\mathrm{CC}, \mathrm{SR}$, and $\mathrm{AC}$ regions from the hybrid classification. This tracking method, similar to that described by Williams and Houze [1987] and Futyan and Del Genio [2007], is based on coincidence overlapping of successive hourly GOES $\mathrm{T}_{\mathrm{IR}}$ data. Each contiguous cloudy region with $\mathrm{T}_{\mathrm{IR}}<235 \mathrm{~K}$ is used to define a cold cloud system for tracking. Only cold cloud systems with a minimum area of $400 \mathrm{~km}^{2}$ ( $\sim 8$ GOES pixels) are tracked by the algorithm. A secondary $\mathrm{T}_{\mathrm{IR}}$ threshold $(215 \mathrm{~K})$ is used to identify areas of strongly depressed IR temperature, labeled as cold cores. Both cold cores and cold clouds are used for tracking the convective systems. If, within two successive $\mathrm{T}_{\mathrm{IR}}$ images, a cloud system overlaps itself by more than $50 \%$ of its area, this cloud system is considered as the same system and its track continues. Tracking is performed iteratively on successive hourly $T_{I R}$ images. Sensitivity tests show that changing the cold cloud $\mathrm{T}_{\mathrm{IR}}$ and area overlap thresholds do not affect any conclusions.

[12] The overlap comparison is performed either going forward or backward in time for all cloud systems that have overlaps. If a cloud system meets the overlap requirement in either tracking direction, it is considered as the same system. When two or more systems merge together, the largest overlapped system is assumed to continue and the smaller overlapped systems are terminated. Similarly, when a cloud system splits into several smaller systems, the largest overlapped fragment continues carrying the characteristics of the original system and the smaller overlapped fragments are labeled as newly formed clouds. The merging and splitting processes are recorded for each time step, thus the systems that experience merging or splitting during their life cycles can be identified in further analysis.

[13] To track the DCSs through their life cycles and to incorporate the large areal coverage of $\mathrm{AC}$ associated with DCSs, the tracked cold clouds are subsequently expanded outward to $\mathrm{T}_{\mathrm{IR}}$ up to $270 \mathrm{~K}$, as defined by the hybrid classification [Feng et al., 2011]. By matching the tracked cold clouds with the hybrid classification, the life cycle of precipitation and cloud structures associated with each DCS are obtained for the following analysis.

[14] Figure 1 illustrates an example of the life cycle of a DCS tracked by the automated tracking method on 14-15 June 2010, with the corresponding classification of CC, SR, and $\mathrm{AC}$ regions. Note that $\mathrm{AC}$ represents all three anvil subcategories (i.e., transitional, thick, thin anvils) as defined by both NEXRAD and GOES data in the hybrid classification [Feng et al., 2011], and characterizes the majority of the anvil clouds associated with the DCS. The system was initially detected at 1715 UTC and grew in size continuously for the following $10 \mathrm{~h}$. At $2215 \mathrm{UTC}$, the system began separating into two parts and eventually at 0015 UTC of 15 June 2010, the relatively smaller system over eastern Oklahoma split from the main system and started a new track system at 0115 UTC (not part of this system and hence not shown). The mature stage of the system (0215-0615 UTC, 15 June 2010) represented a squall line structure of leading CC (red color) and trailing SR (green color), with extensive area of associated peripheral AC (blue color). The system started dissipating at around 0715 UTC and the tracking was eventually terminated at 1315 UTC of 15 June 2010. This particular system developed and matured as an MCS while slowly propagating eastward between the boundaries of Texas and Oklahoma during its life cycle, and was well captured by the automated tracking method.

[15] Radar reflectivity has been widely used to indicate the strength of convective updrafts [Houze et al., 1990; Steiner et al., 1995; Zipser and Lutz, 1994]. For each tracked system, several convective intensity (CI) indices are calculated from the NMQ radar data set, namely the average instantaneous precipitation rates of convective core $\left(P R_{C C}\right)$ and stratiform rain regions $\left(P R_{S R}\right)$, the maximum height of the 45 $\mathrm{dBZ}$ contour in $\mathrm{CC}\left(H_{45 \mathrm{dBZ}}\right.$, proxy for strong updraft as shown by Zipser et al. [2006]), and equivalent radius of the area with reflectivity greater than $30 \mathrm{dBZ}$ at $8 \mathrm{~km}$ height ( $R_{C C 8-\mathrm{km}}$, proxy for the size of intense convective cores, same as that used by Rickenbach et al. [2008]).

[16] Figure 2 shows an example of the evolution of a tracked DCS and its associated cloud top temperature, CC, $\mathrm{SR}$, and AC properties obtained from the hybrid classification during its life cycle. Three stages (developing, mature and dissipating) are defined using the evolution of the DCS equivalent radius and IR temperature following the life cycle stage definition of Futyan and Del Genio [2007]. When a system is detected and tracked, the system is considered as growing vertically and defined as "developing" before it reaches the minimum IR temperature (Figure $2 b$ ). The subsequent period is considered as the "mature" stage when the system reaches the minimum IR temperature and continues to grow in size until reaching its maximum (Figure 2a). The "dissipating" stage is defined after the mature stage when the system decreases in size.

[17] As shown in Figure 2c, CC area grew significantly and reached its maximum size (corresponding to the minimum IR temperature in Figure $2 \mathrm{~b}$ ) during the developing stage and then decreased slowly at the following two stages. SR and AC area coverage also increased rapidly during the developing stage, but they kept a more gradual expansion and reached their respective maximum sizes at the end of the mature stage, and then both decreased sharply in the dissipating stage. As a result of detrained ice and/or mixed phase hydrometeors from the $\mathrm{CC}$ region, the variations of the $\mathrm{SR}$ and $\mathrm{AC}$ area showed similar trends, and their evolutions were closely tied to each other, suggesting that SR and AC are a contiguous cirrus anvil cloud shield and only split by the analyzing technique for rain and no rain. While the SR region has precipitation detected by radars, hydrometeors in 


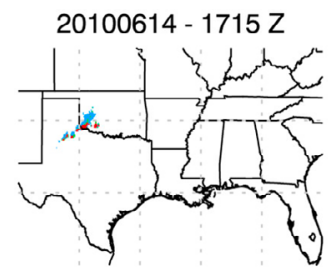

20100614 - 2215 Z

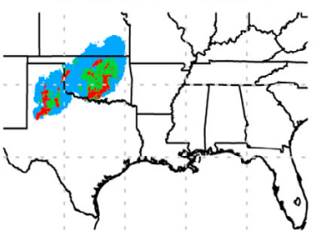

$20100615-0315 z$

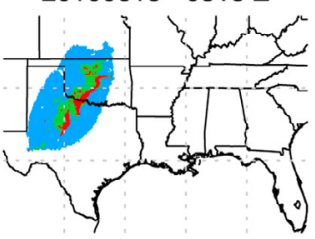

$20100615-0815 Z$

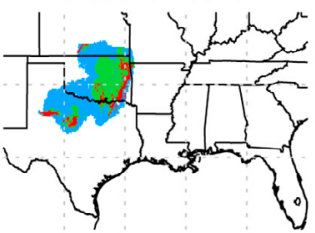

$20100615-1315 z$

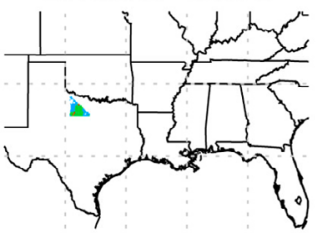

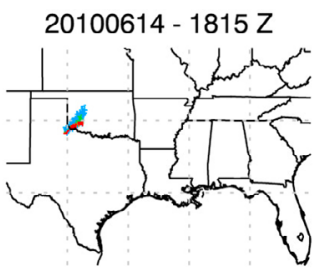

20100614 - 2315 Z

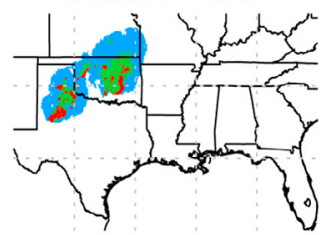

$20100615-0415$ Z

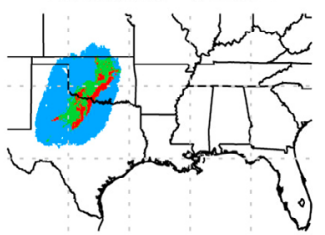

20100615 - 0915 Z

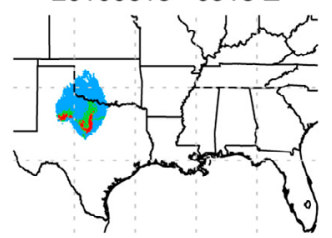

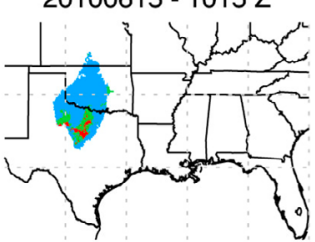

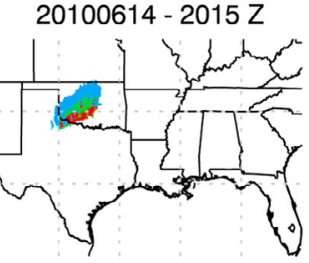

20100615 - 0115 Z

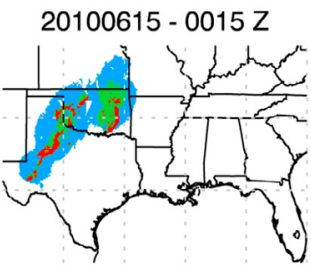

$20100615-0515$ Z

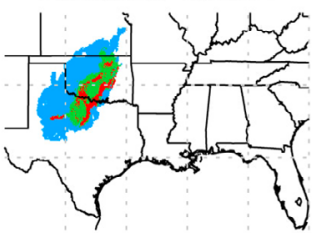

20100615 - 1015 Z
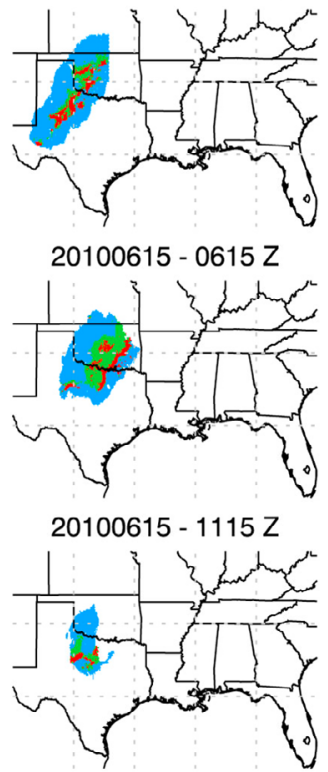

$20100615-0615 Z$

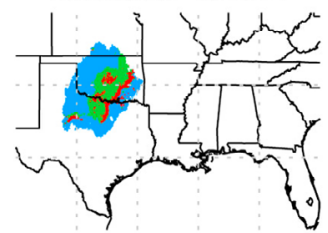

20100615 - 1115 Z

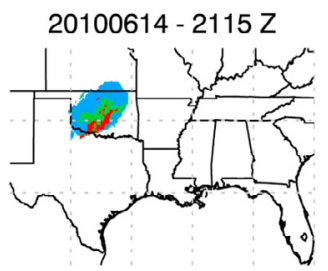

20100615 - 0215 Z

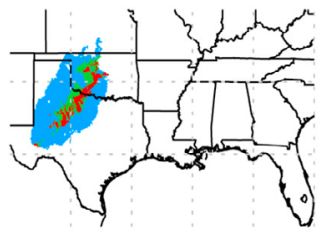

20100615 - 0715 Z

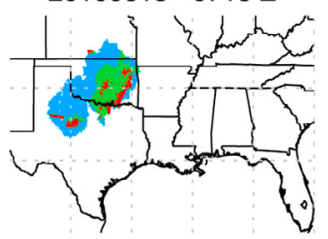

20100615 - 1215 Z

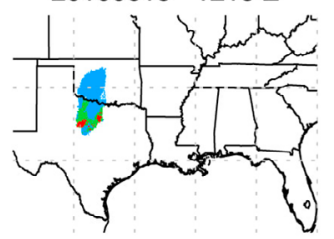

Classification

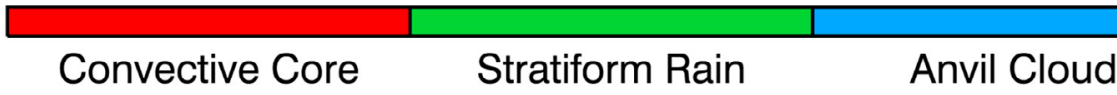

Figure 1. The life cycle of a convective system that is tracked by the automated tracking algorithm in the study domain. Time increases from the top left to the bottom right, and each image represents an hour. The colors represent regions given by the hybrid classification.

the $\mathrm{AC}$ region mostly remain aloft. The several hour lag between peak sizes of stratiform anvil region (both SR and $\mathrm{AC})$ and $\mathrm{CC}$ in Figure 2c indicates the gradual transition from a mostly convective to a more stratiform structure for this particular system. Similar to the life cycle of CC size, both $P R_{C C}$ and $H_{45 \mathrm{dBz}}$ peaked at the early life stage, and then gradually decreased during the mature and dissipating stage (Figure 2d). This example suggests that the CIs examined here peak between developing and mature stages, about at the same time as the maximum CC size but 5-6 h ahead of the maximum SR and AC sizes. Following the same analysis method, the evolution of these properties from all tracked systems are statistically evaluated in the next section.

\section{Evolution of DCS Properties}

[18] A total of 10599 DCSs were tracked during the two warm seasons (May-August) in 2010 and 2011, resulting in an average frequency of 43 DCSs per day over the study domain. The average DCS cloud fraction accounts for $25 \%$ of total clouds observed by GOES satellite $(8 \%$ of total clouds are from precipitating convective and stratiform rain portions of the DCS, and $17 \%$ of total clouds are from anvil clouds), or $47 \%$ of all high clouds, consistent with our previous study [Feng et al., 2011]. In comparison, using $30 \mathrm{~min}$ GOES imagery to track convective systems, Bedka and Minnis [2010] found 877 DCSs in 22 days ( 39 per day) during the 2007 Tropical Composition, Clouds and Climate Coupling Experiment over Central America.

[19] To obtain robust statistics that accurately represent characteristics of DCSs throughout their life cycles, systems with centroids located within $1^{\circ}$ latitude/longitude of the boundaries of the study domain during any time in their life cycle are not used. Further, if the maximum radar coverage area over the entire life cycle of a tracked DCS is less than $70 \%$ of its size, the system is possibly outside the radar coverage area in the ocean or near the Rocky Mountain at the western edge of the domain. Precipitation and anvil structures of these systems are ambiguous and thus excluded from the analysis. With these criteria, the number of systems is reduced to 4221 , or $\sim 40 \%$ of total samples, and their PDFs and CDFs are shown in Figure 3. 

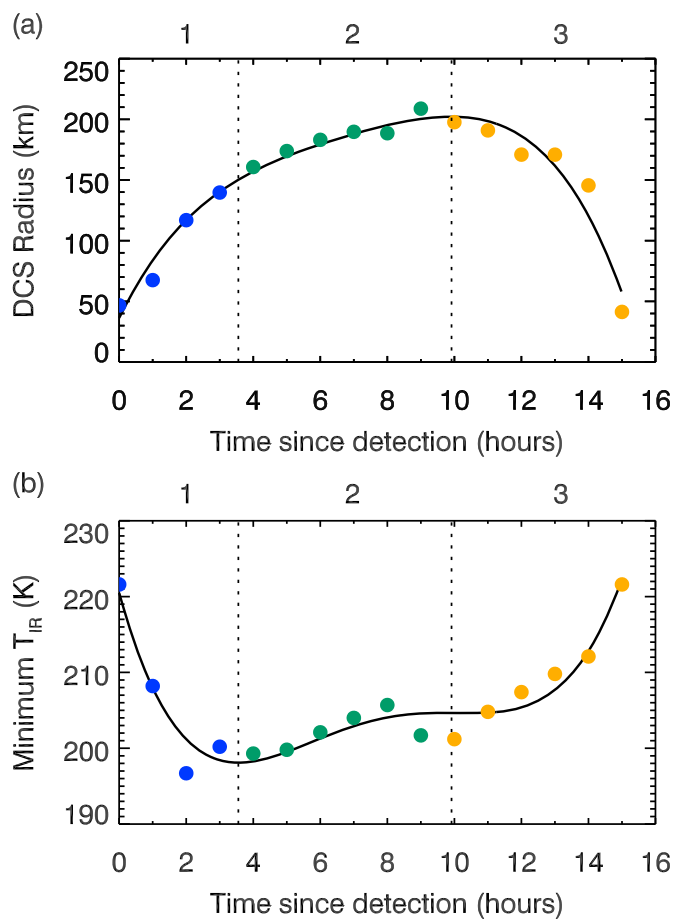

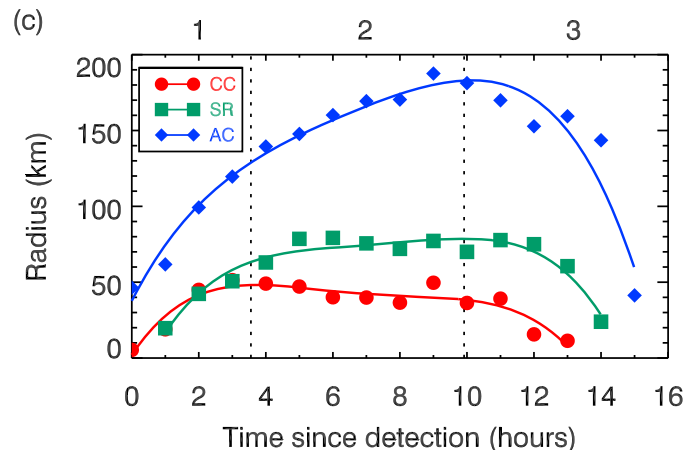

(d)

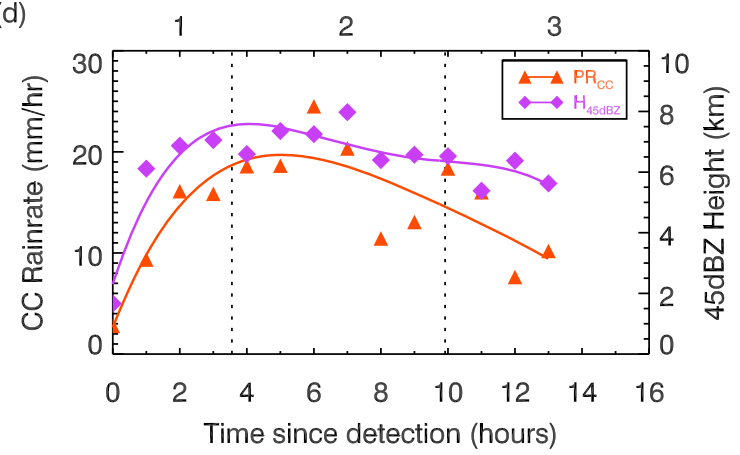

Figure 2. Example of the evolution from a tracked deep convective system (DCS) showing (a) system radius, (b) minimum IR temperature, (c) radii of convective core (CC), stratiform rain (SR), and anvil clouds (AC) calculated from the hybrid classification, and (d) $\mathrm{CC}$ rain rate $\left(\mathrm{PR}_{\mathrm{CC}}\right), 45 \mathrm{dBZ}$ echo top height $\left(\mathrm{H}_{45 \mathrm{dBZ}}\right)$. The radius is defined as the equivalent radius of a circle $(R)$, such that the area is given by $A=\pi R^{2}$. Lines are forth-order polynomial fits, and symbols are observed values. Numbers on top of the panels give the life cycle stage: 1 , developing; 2 , mature; 3 , dissipating.

[20] As expected, system lifetimes decrease exponentially with increasing lifetime (Figure 3a) with a dominant population of short-lived systems (lifetime $<3 \mathrm{~h}, 49 \%$ ), and fewer than $1 \%$ of the systems having a lifetime longer than $14 \mathrm{~h}$. This distribution of lifetimes is comparable to that found by Bedka and Minnis [2010] for a domain centered on Central America. The longest-lasting systems (usually MCSs) contribute significantly to warm season precipitation in the central U.S. and thus are crucial to the hydrological cycle [Carbone et al., 2002]. From the tracked DCS database, the longest-lived systems $(>14 \mathrm{~h})$ contributed $\sim 27 \%$ rainfall and $17 \%$ cloud cover, however, these systems were not included in the statistical analysis due to limited data samples.

[21] Among 4221 analyzed DCSs, $\sim 90 \%$ have an equivalent radius less than $120 \mathrm{~km}$ and a minimum cloud top $T_{\text {IR }}$ lower than $220 \mathrm{~K}$ (Figures $3 \mathrm{~b}$ and $3 \mathrm{c}$ ). Maximum convective core radius $\left(R_{C C}\right)$, stratiform rain radius $\left(R_{S R}\right)$ and anvil cloud radius $\left(R_{A C}\right)$ (Figures $3 \mathrm{~d}-3 \mathrm{f}$ ) are obtained from the hybrid classification. Although the modal values of $R_{C C}$ and $R_{S R}$ are about the same $(\sim 20 \mathrm{~km})$, larger SR occur more frequent than CC (e.g., 90th percentile of $R_{S R}$ is at $60 \mathrm{~km}$ while it is at $35 \mathrm{~km}$ for $R_{C C}$ ). The average area covered by rain from CC and SR during the study period are $28 \%$ and $72 \%$, respectively, similar to the average tropics-wide SR area fraction (73\%) documented by Schumacher and Houze [2003]. Compared to the CC and SR coverage, the AC dominates the DCS area and its distribution (Figure 3f) is similar to that of the DCSs (Figure 3b). At the 90th percentile, the area covered by AC is about three times that of
SR and almost an order of magnitude that of CC. This result is consistent with Feng et al. [2011] over the southern great plains, suggesting that this attribute is representative of the DCSs in the southern and central U.S. region. For the DCSs with reflectivity greater than $30 \mathrm{dBZ}$ at $8 \mathrm{~km}$ MSL height, most of their radii $\left(R_{C C 8-\mathrm{km}}\right)$ are $10 \mathrm{~km}$, with a rapid decrease to $\sim 20 \mathrm{~km}$ at the 90th percentile (Figure $3 \mathrm{~g}$ ) due to few systems with broad areas of intense updrafts supporting large particles at this height. The modal value for maximum $45 \mathrm{dBZ}$ echo top height $\left(H_{45 \mathrm{dBz}}\right)$ is around $5-6 \mathrm{~km}$, with the 90th percentile at a $9 \mathrm{~km}$ height (Figure $3 \mathrm{~h})$. The distributions of average $\mathrm{CC}$ precipitation rates $\left(P R_{C C}\right.$, Figure $\left.3 i\right)$ are similar to those in the SR regions $\left(P R_{S R}\right.$, not shown), except the magnitude of $P R_{C C}$ is an order of magnitude that of $P R_{S R}$. The 90th percentile of $P R_{C C}$ is about $12 \mathrm{~mm} \mathrm{~h}^{-1}$ and $1.4 \mathrm{~mm} \mathrm{~h}^{-1}$ for $P R_{S R}$.

[22] The relationship between total system lifetime and maximum equivalent radius for the tracked DCSs is illustrated in Figure 4. Tracked DCSs that do not experience merging or splitting during their lifetimes are shown separately in blue colors. This analysis found that only $\sim 4 \%$ of the tracked DCSs split into multiple systems. The maximum DCS size attained during DCS life cycles correlates with system lifetime. However, the variance for longer-lived systems increases significantly, similar to the results of Machado et al. [1998] and Pope et al. [2008]. This is possibly due to limited samples observed for large and longlived systems, resulting in larger statistical errors for the averages. When the correlation is calculated based on 
(a)

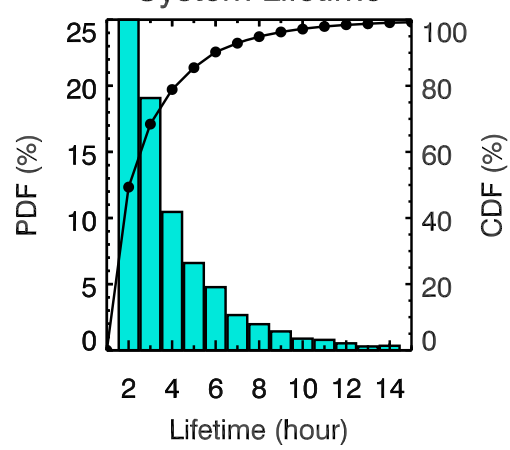

(d) Convective Core

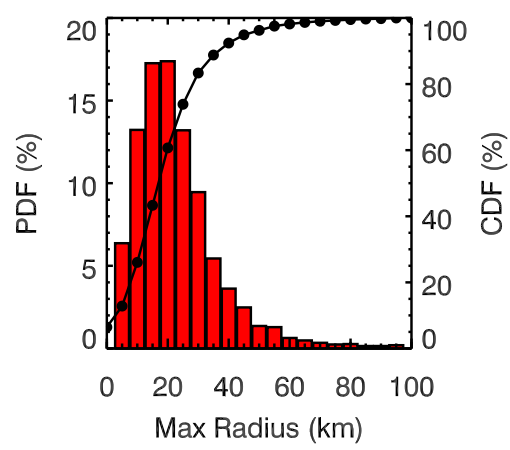

(g) $\quad 8-\mathrm{km}$ CC Radius

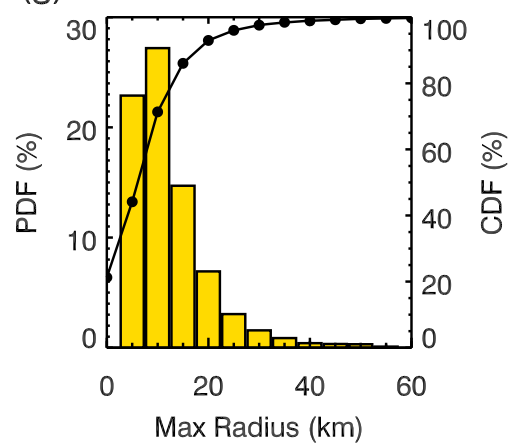

(b)

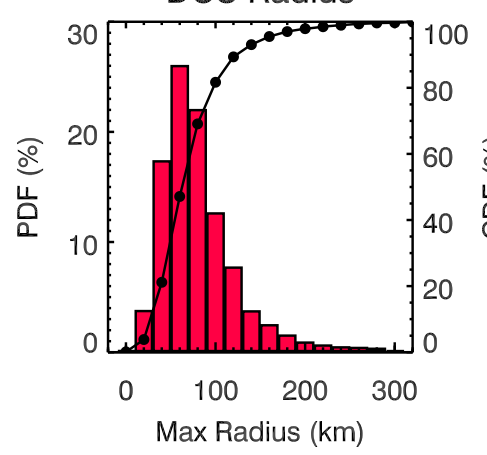

(e)

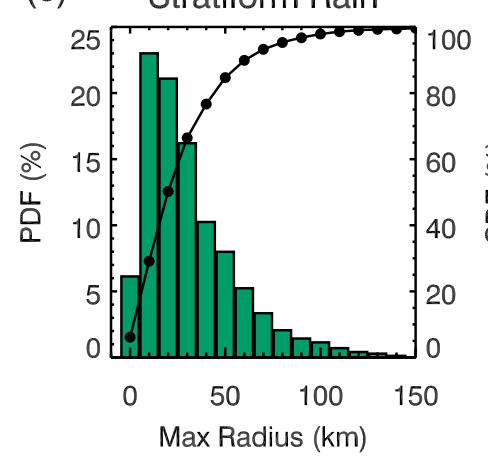

(h)

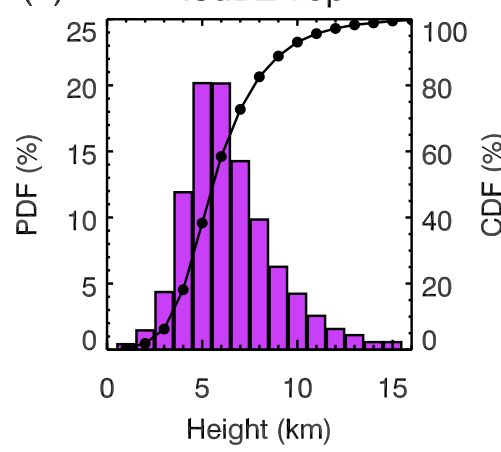

(c)

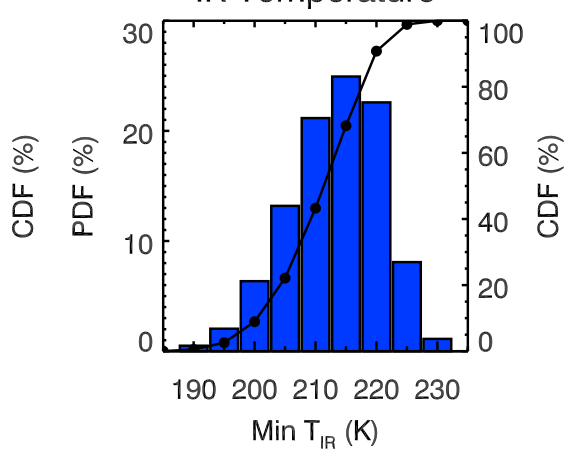

(f)

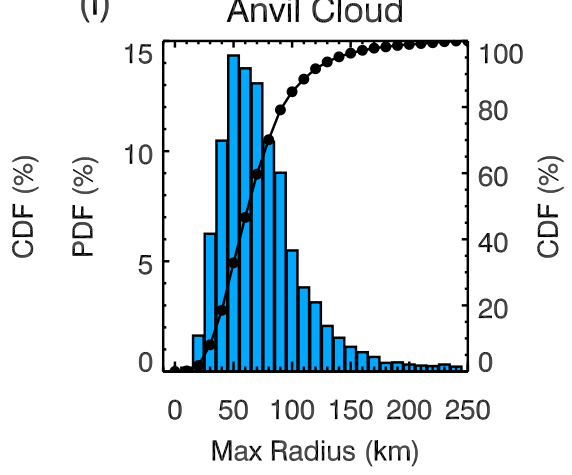

(i) Convective Rainrate

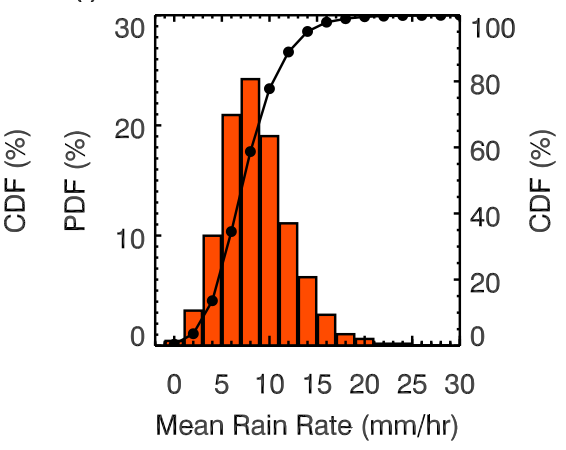

Figure 3. PDF (bars) and CDF (black lines) of (a) system lifetime, (b) maximum size for each tracked DCS, (c) minimum IR temperature, (d) maximum convective core radius $\left(R_{C C}\right),(\mathrm{e})$ maximum stratiform rain radius $\left(R_{S R}\right)$, (f) maximum anvil cloud radius $\left(R_{A C}\right)$, (g) radius of reflectivity greater than $30 \mathrm{dBZ}$ area at $8 \mathrm{~km}$ height $\left(R_{C C 8-\mathrm{km}}\right),(\mathrm{h}) 45 \mathrm{dBZ}$ echo top height $\left(H_{45 \mathrm{dBZ}}\right)$, and (i) convective precipitation rate $\left(P R_{C C}\right)$.

lifetime $<10 \mathrm{~h}$ (red dash line), the average radii for longer systems are still within the range of linear fit lines from the 25 th and 75 th quartiles (shaded area). The maximum sizes of nonmerged systems also correlate with lifetimes up to a period of $10 \mathrm{~h}$. The number of systems decreases dramatically for nonmerged systems at lifetimes longer than $10 \mathrm{~h}$, suggesting that long-lasting DCSs usually experience merging with other systems. These results are consistent with those of Jirak et al. [2003] in that more than 70\% of their MCS samples evolved from the merger of multiple convective clusters. Comparisons between merged and nonmerged systems in this study (not shown) suggest that the major differences are system lifetime and maximum size attained, while other Convective Intensity (CI) indices are similar.

[23] To examine the evolution of CC, SR and AC of the tracked DCSs, the equivalent radii of these three components are composited and illustrated in Figure 5 based on their lifetimes following the method used by Pope et al. [2008]. It is apparent that the maximum sizes of the three major DCS components attained during their life cycles also correlate with system lifetime, i.e., longer-lived DCSs are consistently larger in size with more extensive stratiform rain and anvil cloud shields. This correspondence between system lifetime and maximum size is consistent with findings of Chen and Houze [1997] and Pope et al. [2008], suggesting systematic 


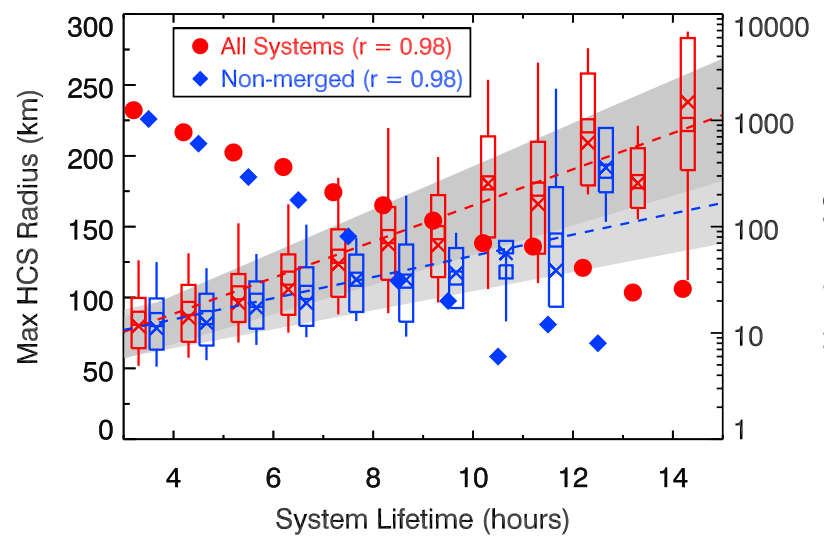

Figure 4. The maximum DCS equivalent radius as a function of system lifetime. Red colors are all systems including merged systems, and blue colors denote nonmerged systems. The box covers the 25 th-75th percentiles, and the whisker covers the 10th-90th percentiles. The square indicates the mean value, and the cross denotes the median value. The dashed lines are linear function fitting using mean values for all systems up to $10 \mathrm{~h}$ (red) and for nonmerged systems up to $7 \mathrm{~h}$ (blue), with corresponding correlation coefficients shown in parentheses. The shaded areas are the same linear fits except using the 25 th and 75 th percentile values, with dark gray from all systems and light gray from nonmerged systems. Solid circles and diamonds are the number of systems for each lifetime bin.
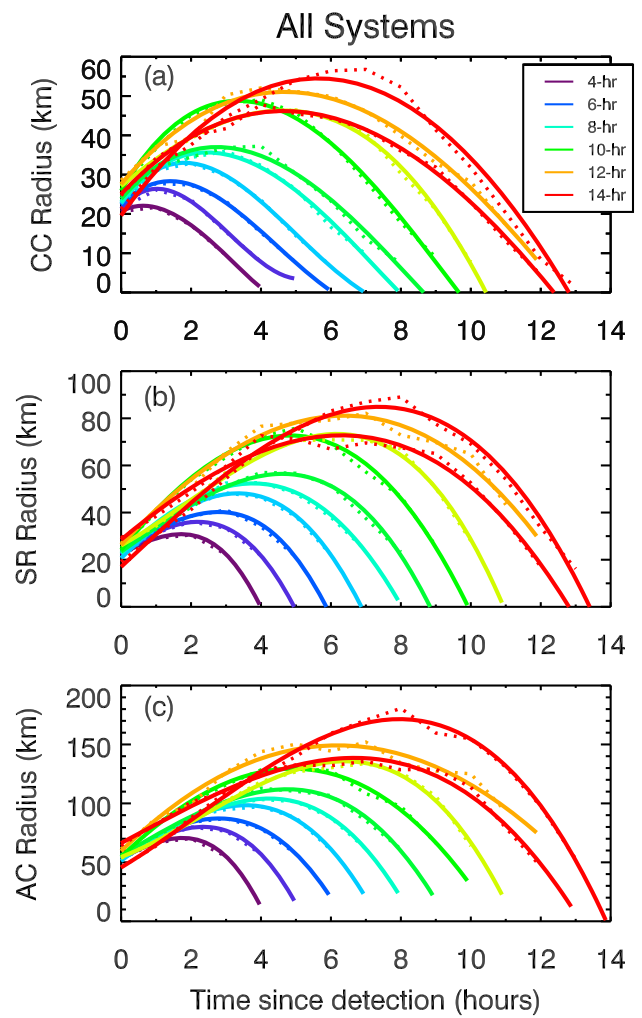

similarities between tropical and midlatitude DCSs. Comparing the life cycles of $R_{C C}$ (Figures $5 \mathrm{a}$ and $5 \mathrm{~d}$ ) with those from $R_{S R}$ and $R_{A C}$ (Figures $5 \mathrm{~b}, 5 \mathrm{c}, 5 \mathrm{e}$, and $5 \mathrm{f}$ ), it appears that the size of CC peaks always lead those of SR and $\mathrm{AC}$ by a few hours for all lifetimes and system sizes. Since $R_{S R}$ and $R_{A C}$ are highly correlated (correlations $>0.95$ for all systems with the range of lifetimes shown in Figure 5), $R_{A C}$ is used to represent the entire mesoscale stratiform cloud deck (SR + AC) of these systems.

[24] To understand the phase relationship between convective intensity and stratiform cloud coverage, Figure 6 shows the lag between peak CI indices and maximum $R_{A C}$. It is clear that this lag increases linearly with system lifetime, regardless of which CI index is used although the increase calculated from $R_{C C}$ is $\sim 40 \%$ slower than those from the other three CIs. The radar-reflectivity-texture-based CC/SR partitioning [Steiner et al., 1995] used in the hybrid classification tends to produce excessive CC and low SR area in enhanced SR rain [Lang et al., 2003], thus delaying the peak in $R_{C C}$. Nevertheless, all of the CIs indicate that the increasing lag with system lifetime is a robust signal. The lag increases from $\sim 1 \mathrm{~h}$ for $4 \mathrm{~h}$ long systems to more than $3 \mathrm{~h}$ for $14 \mathrm{~h}$ long systems.

[25] Occurrence of the peak convective intensity and stratiform cloud region (SR and AC) portions of DCSs at different times has important implications for climate model simulations. In the life cycle of DCSs, precipitation evolves from predominately convective in the early stage to more stratiform in the mature to decaying stage. The
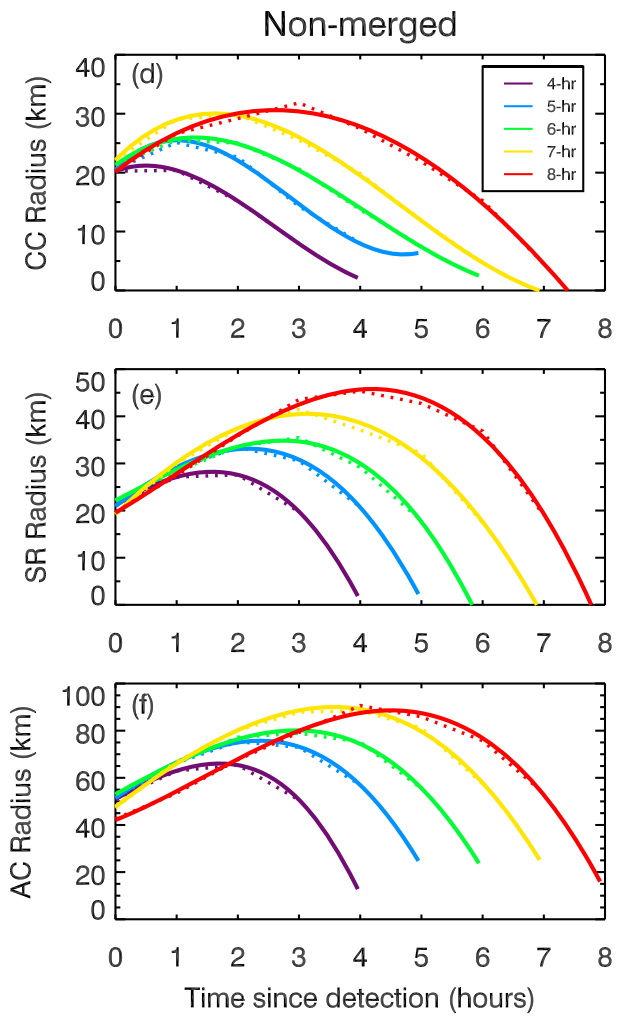

Figure 5. Averaged system evolution for the three major components of the tracked DCSs. (left) All systems, including merged systems, and (right) systems that do not merge or split. (a, d) Convective core (CC), (b, e) stratiform rain (SR), and (c, f) anvil cloud (AC). Dotted lines are hourly mean observed values, and solid lines are third-order polynomial fits. 


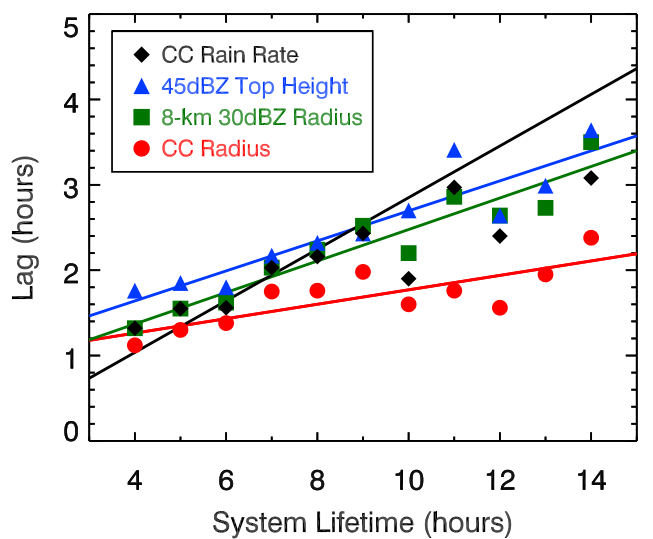

Figure 6. Composite lag between maximum stratiform rain (SR) or anvil cloud (AC) area and peak convective intensity indices as a function of system lifetime.

accompanying diabatic heating structures shift from the first baroclinic mode, which has heating throughout the troposphere, to the second baroclinic mode, which has heating in the upper troposphere and cooling below [Houze, 1989]. This change in the heating structure generates mesoscale circulations in the upper troposphere that helps maintain the systems, particularly for the stratiform area (SR and $\mathrm{AC}$ ), thus, prolonging the lifetime of systems. Note that microphysics also plays an important role. For example, incorrect hydrometeor size distributions in either CC or SR regions, or poor particle fall velocity assumptions in model simulations will result in failure to reproduce the observed structures in both $\mathrm{CC}$ and $\mathrm{SR}$ region [Varble et al., 2011], and the time delay characteristic between the convective and stratiform cloud region.

[26] In a comparison of Australian monsoon season MCSs simulated by a cloud resolving model (CRM) during the active and break periods of the Tropical Warm Pool-International Cloud Experiment (TWP-ICE), Del Genio et al. [2012] found $\sim 4 \mathrm{~h}$ difference in lags between the SR region and convection during the two periods. They hypothesized that in a drier and less convectively sustainable environment, SR area is restricted to the amount of hydrometeor detrainment from $\mathrm{CC}$, and the detrained ice sublimes with no development of mesoscale circulations. In contrast, in a moist environment, upper tropospheric relative humidity (RH) is almost water saturated, and detrainment of buoyant air initiates a mesoscale updraft in the upper troposphere. High RH provides an environment favorable for sediment ice to grow further by deposition, releasing latent heat and eventually generating mesoscale updraft that maintains SR for hours. The much longer lag time represents the time it takes for mesoscale updraft to develop and maintain the SR region.

[27] According to this hypothesis, the increased lag between maximum SR area and peak CI can be explained as follows. In an environment favorable (or "sustainable") for convective development (e.g., deeper moisture, higher CAPE, stronger wind shear, and/or presence of a low-level jet as suggested by Coniglio et al. [2010]), longer-lived DCSs/MCSs are more likely to form than shorter-lived systems. Once convection develops, ambient upper level wind spreads out the initial detrained ice from the $\mathrm{CC}$, and the humid upper tropospheric environment allows development of mesoscale updrafts through deposition growth of sediment ice that releases latent heat. This process takes several hours until the mesoscale stratiform cloud region is fully developed. As a result, the lag between maximum SR and $\mathrm{AC}$ area and peak CI for long-lived systems is considerably larger than that for the short-lived ones. The relationship between system lifetime, convective organization and the environment will be further investigated in section 4 .

[28] Note that the 1-3 h lags in Figure 6 represent the composite mean of all tracked systems. A 1-2 h lag between maximum convective rainfall and system cloud cover was reported by Rickenbach et al. [2008] for several isolated convective cells in south Florida. The dry and suppressed environment in their study and lack of mesoscale organization represents the "unsustainable" environment and resembles the low end of the lag. Individual DCSs in this study show much larger spread of lags. The calculated standard deviation of lags has a range of $0-7 \mathrm{~h}$, with the upper end comparable to the TWP-ICE moist case shown by Del Genio et al. [2012]. Nevertheless, the composite lags show the increased staggered timing between convective and stratiform latent heating, and radiative heating from anvil clouds. Latent heating profiles associated with convective clouds are positive throughout the troposphere due to active condensation of droplets, while stratiform profiles have heating above the melting level due to condensation/deposition and cooling below due to evaporation of rain [Schumacher et al., 2004]. Radiative heating profiles from optically thick AC are positive at $\mathrm{AC}$ base (between middle and upper troposphere) and negative at $\mathrm{AC}$ top, while optically thin cirrus have radiative heating throughout the cloud [Ackerman et al., 1988; Garrett et al., 2005; Jensen and Del Genio, 2003; Powell et al., 2012]. As a result of DCSs transitioning from convective to stratiform structure, the positive latent heating shifts to the upper troposphere, and is further enhanced by the radiative heating from $\mathrm{AC}$ due to the concurrent peak of the SR and AC regions. The increased staggered timing with overall system lifetime suggests that changes in the overall diabatic heating structure could help maintain the systems through mesoscale ascent, prolonging the system lifetime by sustaining SR and AC development.

[29] The lack of mesoscale organization in most current generation GCMs prevents them from even forming a SR region [Del Genio et al., 2012], let alone correctly simulating the staggered timing. CRMs have the ability to produce mesoscale features associated with DCSs through explicit simulation of cloud microphysics, although they have not yet produced realistic radar observed stratiform structures [Varble et al., 2011]. The evolution of the CC/SR/AC regions and their staggered timing, found in this study, should be compared with more CRM simulated cases to diagnose the mechanisms responsible for transition from $\mathrm{CC}$ to $\mathrm{SR}$ and $\mathrm{AC}$, and provide further guidance for parameterizing these processes in GCMs.

\section{Factors Affecting Anvil Production}

[30] For GCMs to predict how much stratiform rain (SR) and anvil clouds (AC) are produced from deep convection, it is important to determine the factors affecting their 


$$
R_{\text {multi }}=0.69
$$

(a)

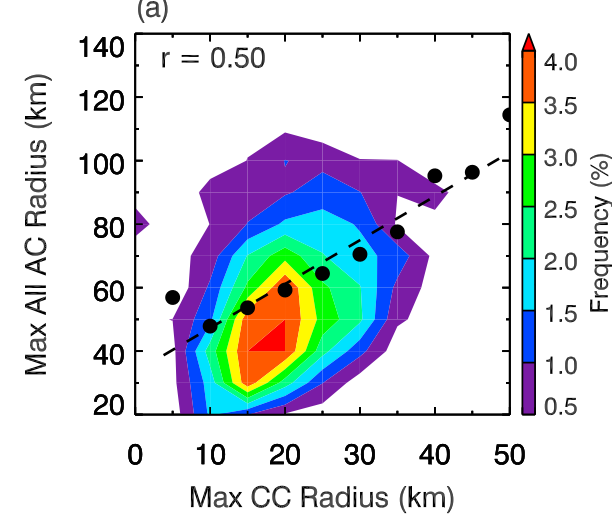

(c)

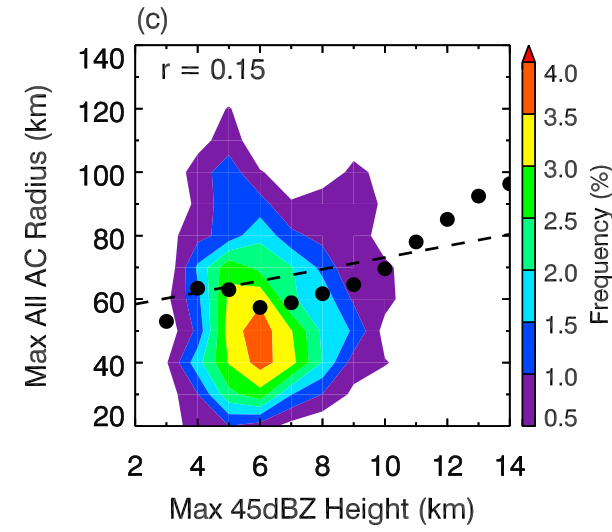

(e)

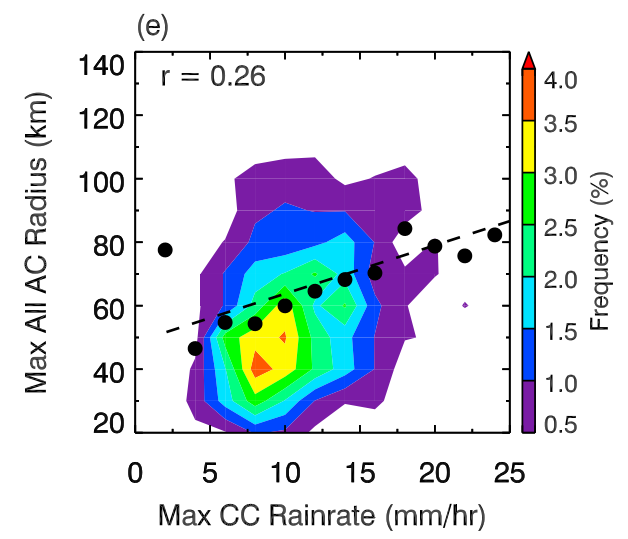

(b)

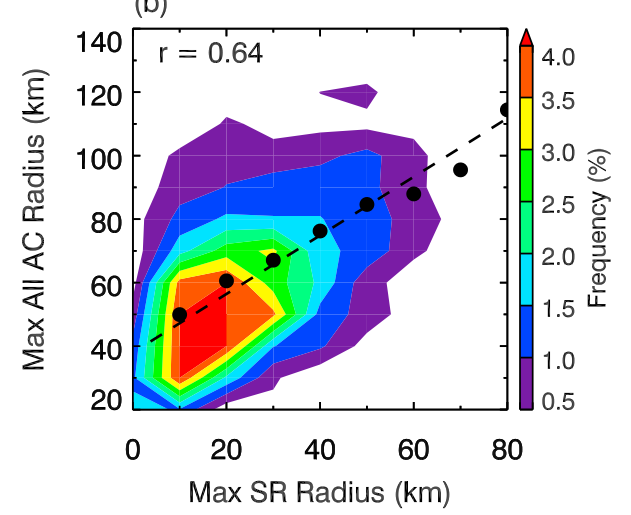

(d)
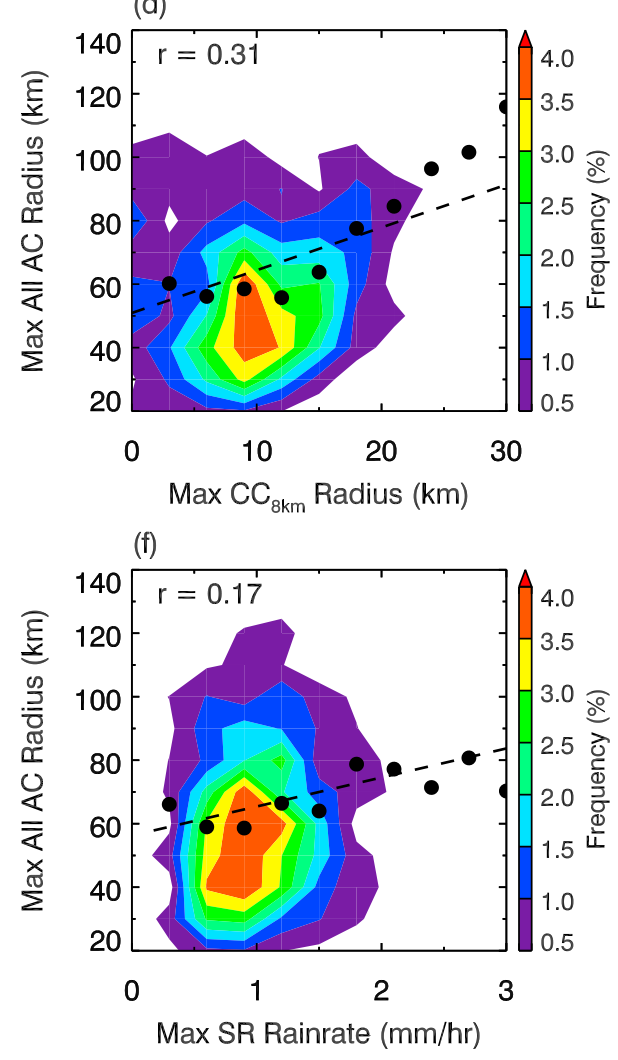

Figure 7. Frequency distribution of the maximum anvil cloud radius as a function of various convective intensity (CI) indices during developing and mature stages. (a) CC radius, (b) SR radius, (c) $45 \mathrm{dBZ}$ echo top height, (d) radius of $30 \mathrm{dBZ}$ area at $8 \mathrm{~km}$ height, (e) $\mathrm{CC}$ rain rate, and (f) SR rain rate. Black dots represent median $\mathrm{AC}$ values for each $\mathrm{CI}$ bin, the dashed line is the linear fit line from all raw samples, and $\mathrm{r}$ is the correlation coefficient. Results are computed using systems that do not experience merging or splitting during their life cycles.

production so that these relationships can be correctly parameterized in the models. We explore the relationship between the size of AC and various Convective Intensity (CI) indices, as well as the environment, with the intent of determining which factors are most relevant to the convective AC production over the study domain. To avoid influence from processes not related to the internal dynamics, the results in this section only use systems that did not experience any merging or splitting during their entire life cycles. The number of systems is reduced to
$3450(81.7 \%$ of the original sample number), and most of these systems have lifetimes shorter than $10 \mathrm{~h}$ (Figure 4).

[31] Figure 7 shows the frequency distributions of $\mathrm{AC}$ radius as functions of a variety of DCS properties. AC radius $\left(R_{A C}\right)$ and DCS properties are reported as the maximum values obtained during the developing and mature stages of the systems (see Figure 2). Similar to the results found in Figure $5, R_{A C}$ correlates well with $\mathrm{CC}$ radius $\left(R_{C C}\right)$ and $\mathrm{SR}$ radius $\left(R_{S R}\right)$ (Figures $7 \mathrm{a}$ and $7 \mathrm{~b}$ ), with correlation coefficients of 0.50 and 0.64 , respectively. The strong correlation 
between $\mathrm{AC}$ and $\mathrm{SR}$ is expected because $\mathrm{SR}$ and $\mathrm{AC}$ are essentially a contiguous stratiform cloud deck from DCSs. Similar correlations between convective area and anvil area were found by Li and Schumacher [2011] in several tropical regions using TRMM precipitation radar data. However, anvil area was only weakly correlated with stratiform rain area in their study, possibly due to the low sensitivity of TRMM precipitation radar to nonprecipitating anvil clouds or to the narrow TRMM radar swath, which may not have completely observed some very large DCSs.

[32] The correlation between $R_{A C}$ and several other CI indices (Figures $7 \mathrm{c}-7 \mathrm{f}$ ), namely the $45 \mathrm{dBZ}$ echo top height $\left(H_{45 \mathrm{dBZ}}\right)$, the radius of $30 \mathrm{dBZ}$ area at $8 \mathrm{~km}\left(R_{C C-8 \mathrm{~km}}\right), \mathrm{CC}$ precipitation rate $\left(P R_{C C}\right)$ and $\mathrm{SR}$ precipitation rate $\left(P R_{S R}\right)$, are much lower than those of $R_{C C}$ and $R_{S R}$. The entire anvil cloud shield associated with a mature DCS (i.e., $R_{A C}$ ) consists of two parts: thick AC consisting of large hydrometeor particles that is still attached to CC or SR areas, and thin AC consisting of cirrus that is a remnant of the SR or thick AC region [Houze, 1993; Li and Schumacher, 2011]. In the hybrid classification, the former is classified by NEXRAD radar, and the latter is identified by the GOES data. On average, thick anvils are $27 \%$ of the total anvil cloud fraction during the study period. One possible reason for the low correlation between total $\mathrm{AC}$ size and $\mathrm{CI}$ is that thin $\mathrm{AC}$, usually located furthest away from the active precipitating area, is less directly impacted by the parent convection and more likely influenced by the environment such as wind shear, moisture and radiative forcing from the atmosphere and surface underneath [Garrett et al., 2005; Rickenbach et al., 2008].

[33] To investigate this possibility, each of the CI indices was correlated with the radius of thick AC (not shown). The resulting correlation coefficients with $H_{45 \mathrm{dBZ}}, R_{C C-8 \mathrm{~km}}$, and $P R_{C C}$ increased to $0.40,0.59$ and 0.35 , respectively. The multivariate correlation coefficient between all CIs (shown in Figure 7) and the thick AC also increased to 0.79, compared to 0.69 for the total AC. Therefore, the most important factors that control the areal extent of thick $\mathrm{AC}$ are: the size of CC $\left(R_{C C}, R_{C C-8 \mathrm{~km}}\right)$ and the strength of convective updraft (proxies by $H_{45 \mathrm{dBz}}, P R_{C C}$ ). Del Genio et al. [2012] noted that cumulus mass flux, defined as convective area times the mean updraft speed, is the best predictor for the SR area in their model simulation. The result in this paper is qualitatively consistent with that suggested by Del Genio et al. [2012].

[34] To investigate the relationship between the environment and AC production, vertical profiles of atmospheric state variables from the NARR reanalyses were matched with the tracked DCSs. The results from NARR were calculated using data between May and August 2010 because the 2011 NARR data set has not been released at the time of this paper. Figure 8 shows the composite profiles of zonal and meridional wind, relative humidity $(\mathrm{RH})$, and vertical motion as a function of the maximum $\mathrm{AC}$ area attained during the developing and mature stages of the tracked DCSs. It is evident from the zonal wind composite (Figure 8a) that DCSs with larger AC area are associated with stronger upper level wind between 150 and $200 \mathrm{mb}$ and deep layer wind shear. For example, the average wind speed between 150 and $200 \mathrm{mb}$ for systems with $R_{A C}>120 \mathrm{~km}$ is
$24 \%$ higher than those with $R_{A C}=20 \mathrm{~km}$. The upper tropospheric bulk wind shear (wind speed difference between $150 \mathrm{mb}$ and $600 \mathrm{mb}$ ) increases $\sim 20 \%$ monotonically from $13.2 \mathrm{~m} \mathrm{~s}^{-1}$ (for $R_{A C}=20 \mathrm{~km}$ ) to $15.9 \mathrm{~m} \mathrm{~s}^{-1}$ (for $R_{A C}>120$ $\mathrm{km})$. The evidence of stronger upper level wind speed and deep layer wind shear enhancing AC production is similar to that shown by Li and Schumacher [2011] over tropical Africa and South America.

[35] RH profiles (Figure 8c) do not show much difference in the upper troposphere, but instead larger ACs are associated with slightly lower RH in the midtroposphere between 300 and $600 \mathrm{mb}$. One possible explanation is that for DCSs with very little AC, the NARR profiles in the AC region are more representative of the $\mathrm{CC}$ and SR region, and, therefore, they yield higher RH than systems with larger AC, which would be further away from active convection. Another possible reason is that errors and/or biases in upper tropospheric DCS moisture profiles produced by NARR prevent any significant signals to be obtained.

[36] Vertical pressure velocity (Figure 8d) shows rising motion throughout the middle to upper troposphere for all systems investigated. Systems with smaller ACs $\left(R_{A C}<80\right.$ $\mathrm{km})$ tend to have stronger vertical motion, possibly for the same reason suspected for the greater $\mathrm{RH}$, that the data are sampled closer to the convection. For systems with larger ACs $\left(R_{A C}>80 \mathrm{~km}\right)$ the rising motion between 150 to $600 \mathrm{mb}$ increases with $\mathrm{AC}$ radius. We note that results from the vertical motion analysis should be treated with caution because comparisons between NARR, sounding and other reanalysis data sets show significant differences in vertical motion during the warm season at the Atmospheric Radiation Measurement (ARM) southern great plains site in Oklahoma [see Kennedy et al., 2011, Figure 4]. However, zonal and meridional wind fields from NARR compare favorably with ARM soundings, and RH also agrees well until above $300 \mathrm{mb}$ where NARR has a $10-15 \%$ bias [Kennedy et al., 2011].

[37] Since the eventual size of the DCS is undeniably influenced by the lifetime of the system (Figure 4), the maximum size of $\mathrm{AC}$ attained is also related to its lifetime. Machado and Laurent [2004] found that the cloud area expansion rate at the initial stage of convection is a good indicator for system lifetime. The area expansion rate is defined as:

$$
A_{e}=\frac{1}{A} \frac{\partial A}{\partial t}=\nabla \cdot \mathbf{V}+\frac{1}{Q} \frac{\partial Q}{\partial t}
$$

where $A$ is the convective system area defined by satellite $\mathrm{T}_{\mathrm{IR}}<235 \mathrm{~K}, \nabla \cdot \mathbf{V}$ is the upper level wind divergence, and $Q$ is the water content of the convective system [Machado and Laurent, 2004, equation (8)]. They suggested that a rapidly growing DCS is a result of strong liquid water condensation and vertical mass flux, along with increasing upper air wind divergence.

[38] To test this hypothesis, area expansion rate and two radar-derived convective intensity indices of the initial hour are plotted as a function of total system lifetime in Figure 9. It is apparent that the area expansion rate exponentially increases with system lifetime until $\sim 6 \mathrm{~h}$, but the relationship no longer holds for lifetimes longer than $8 \mathrm{~h}$. Rain rate 
(a)

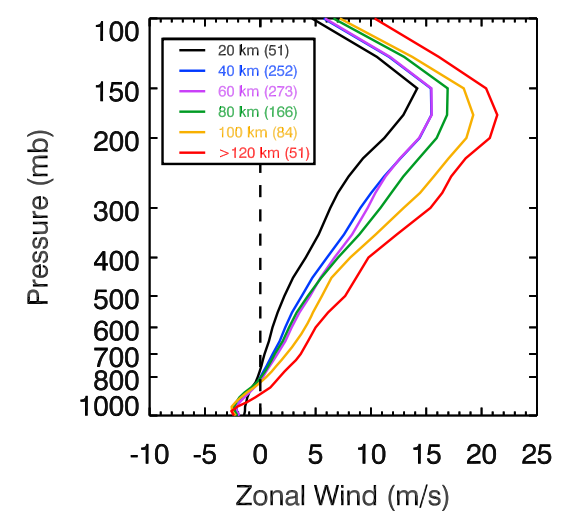

(c)

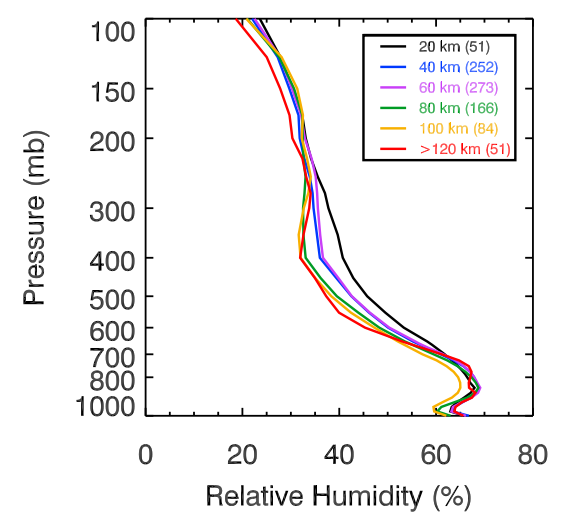

(b)

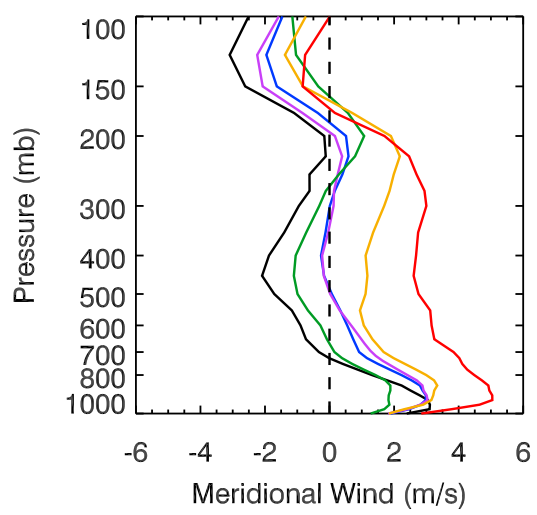

(d)

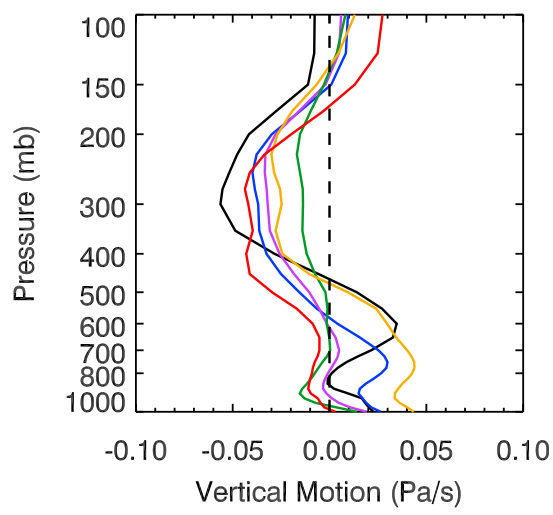

Figure 8. Composite NARR atmospheric state profiles as a function of the maximum AC radius attained during developing and mature stages of convection. (a) Zonal wind, (b) meridional wind, (c) relative humidity, and (d) vertical pressure velocity (negative is upward). The profiles are obtained during developing and mature stages of each system and averaged within all anvil cloud regions; the numbers in the parentheses indicate the number of systems for that profile.

and $30 \mathrm{dBZ}$ echo top height show similar trends, except that the average $30 \mathrm{dBZ}$ echo top height continues increasing with lifetime up to $10 \mathrm{~h}$ while the relationship with convective rain rate becomes ambiguous for lifetime longer than $6 \mathrm{~h}$. Nevertheless, these relationships support the findings of Machado and Laurent [2004] that rapid growth of convective systems in the initial hour is a result of strong water condensation associated with vigorous convective forcing (e.g., strong low-level convergence, upper level divergence and vertical updraft). The results suggest that the lifetime of short to medium (less than $6 \mathrm{~h}$ ) DCSs is strongly affected by the intensity of convection at the initial stage. However, for DCSs with longer lifetimes the vigor of initial convection no longer explains the system lifetime. Other factors such as a convectively favorable environment and the organization of convection must play a role to sustain DCSs lasting longer than $6 \mathrm{~h}$.

[39] To further investigate the impact of environmental factors on system lifetime, NARR reanalysis fields were composited based on the lifetime of systems as illustrated in Figure 10. NARR profiles within the CC and SR regions were averaged to obtain the composite. Compositing NARR within other regions of DCSs does not show significant differences, suggesting the signals are robust among different system lifetimes. Similar to Figure 8, NARR profiles during the developing and mature stages of the tracked DCSs are used for the composite. To maintain a robust classification of DCS life stage, only systems with lifetime longer than $3 \mathrm{~h}$ are considered.

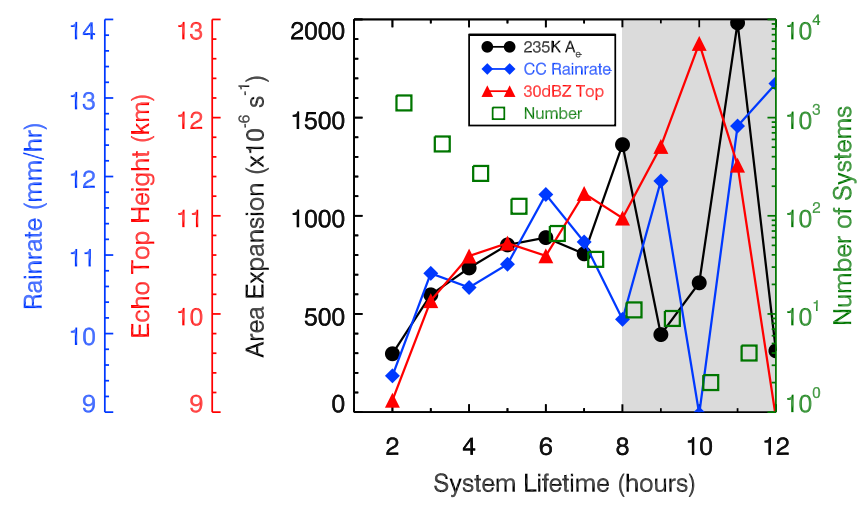

Figure 9. Average convective intensity at the initial hour as a function of the convective system lifetime. Area expansion rate $\left(A_{e}\right)$ is calculated using cloud area with $\mathrm{T}_{\mathrm{IR}}<235 \mathrm{~K}$, and convective rain rate and $30 \mathrm{dBZ}$ echo top height are derived from radar data. The shaded area indicates the number of systems less than $1 \%$ of the total sample number. 
(a)

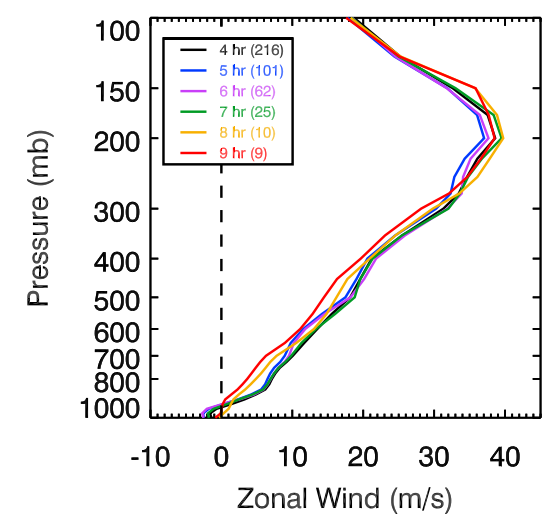

(c)

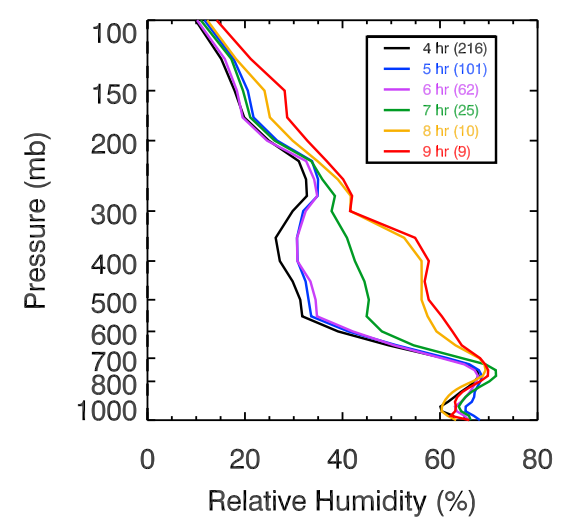

(b)

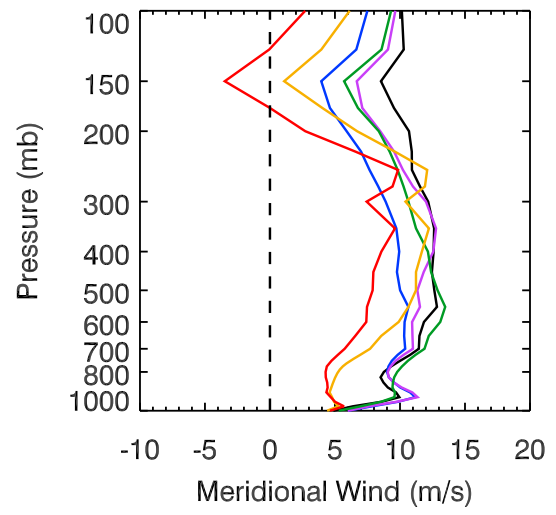

(d)

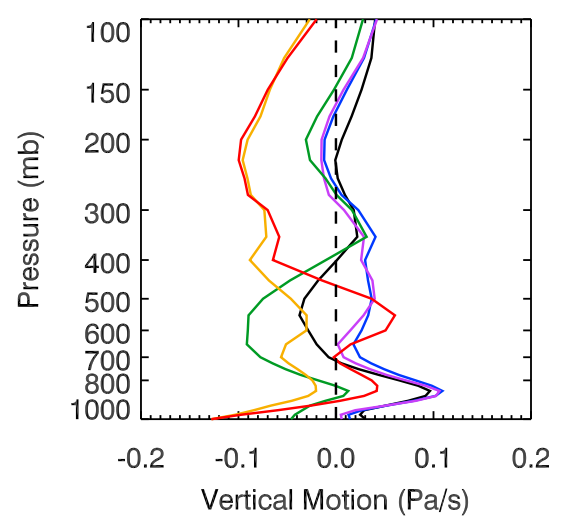

Figure 10. Same as Figure 8, except composited as a function of system lifetimes. The profiles are obtained during developing and mature stages of each system and averaged within the convective and stratiform rain region.

[40] While zonal wind profiles do not appear much different between various system lifetimes, meridional wind shows stronger deep layer shear associated with longerlasting systems. The bulk wind shear (between 150 and $600 \mathrm{mb}$ ) values are similar between 4 and $6 \mathrm{~h}$ lifetime systems $\left(\sim 20 \mathrm{~m} \mathrm{~s}^{-1}\right)$, but monotonically increase to $27 \mathrm{~m} \mathrm{~s}^{-1}$ for $9 \mathrm{~h}$ lifetime systems ( $40 \%$ increase). $\mathrm{RH}$ differences between various system lifetimes are largest in the midtroposphere. Similar to wind shear, RH show little differences between 4 and $6 \mathrm{~h}$ lifetimes, but the mean $\mathrm{RH}$ value between 300 and $700 \mathrm{mb}$ increases from $39 \%$ for $6 \mathrm{~h}$ systems to $58 \%$ for $9 \mathrm{~h}$ systems ( $\sim 50 \%$ increase). The differences between these profiles suggest that longerlasting systems (more than $6 \mathrm{~h}$ ) tend to occur in a convectively favorable environment (i.e., stronger wind shear and higher humidity), where SR region can fully develop several hours after the initial vigorous convection (Figure 6). While it is possible that high RH is partially caused by detrainment or evaporation/sublimation in the CC/SR region (i.e., NARR is contaminated by the convective signal), we argue that this is not the main reason for the difference because averaging the NARR profiles in the thin $\mathrm{AC}$ region (i.e., furthest away from the influence of convection) lead to similar conclusion.

[41] Stronger deep layer wind shear and moisture associated with longer-lived convective systems are consistent with previous studies of MCS environments in the United States [Cohen et al., 2007; Coniglio et al., 2007, 2010]. Vertical pressure velocity shows that short-lived systems are mostly associated with neutral to slightly downward motion throughout the troposphere, while longer-lived systems are related to upward motion in the middle to upper troposphere, consistent with mesoscale circulations in the SR region. The vertical velocity profile for $9 \mathrm{~h}$ lifetime systems shows transitioning from rising to sinking motion at around $500 \mathrm{mb}$. This is possibly due to cooling in the extensive SR region associated with long-lasting systems (Figure 5e) creating downward motion that eventually dominates the large-scale rising motion in the reanalysis.

[42] Combining the evidence from Figures 6, 9, and 10, the following interpretation of DCS lifetime is provided. For short to medium systems (lifetimes less than $6 \mathrm{~h}$ ), the lifetime is mainly attributed to the intensity of the initial convection. More rapid expansion at the initiation stage signifies stronger initial convective forcing, resulting in longer system lifetime. For systems that last longer than $6 \mathrm{~h}$ without merging with other systems, vigorous initial convection alone is not sufficient to explain their lifetime. A moist midtroposphere with stronger deep layer wind shear is necessary to allow convection to fully deepen, providing an environment favorable for the growth of detrained water 
condensates by deposition, releasing latent heat in the process and supporting further development of $\mathrm{SR}$ and $\mathrm{AC}$ region. Full development of the SR and AC regions takes a few hours longer after the initial intense convection, thus prolonging the lifetime of convective systems beyond $6 \mathrm{~h}$. By incorporating radar and satellite data in a Lagrangian approach, and building on the findings of Machado and Laurent [2004] and Del Genio et al., [2012], this study provides interpretation of convective organization and the relationship between DCS lifetime, cloud properties, and their dynamic and thermodynamic environments.

\section{Summary and Conclusion}

[43] In this study, an automated satellite tracking method was used in conjunction with a multisensor hybrid classification to analyze the life cycle of precipitation and cloud structures associated with midlatitude deep convective systems (DCSs) in a Lagrangian framework during two warm seasons (May-August 2010-2011) over the central United States.

[44] On average, the frequency of occurrence for all DCSs tracked by the automated satellite tracking method is $\sim 43$ day $^{-1}$ during the study period. The average DCS cloud fraction accounts for $25 \%$ of total clouds as observed by GOES satellite, with $8 \%$ of total clouds from precipitating deep clouds. The majority of the tracked systems have lifetimes shorter than $14 \mathrm{~h}$, and the analysis is confined within the southern and central United States where these systems are well covered by both NEXRAD radars and GOES satellite. The number of systems decreases exponentially with increasing lifetime, and $\sim 51 \%$ of the systems have a lifetime of $3 \mathrm{~h}$ or longer. Anvil clouds (AC) dominate the DCS area, covering an area about three times that of stratiform rain (SR) area and an order of magnitude that of the convective core (CC). SR accounts for $72 \%$ of the precipitation area, similar to the tropicswide average SR area fraction reported in other studies. Maximum system size attained during their life cycles correlates with system lifetime. Merged and nonmerged systems mainly differ in lifetime and maximum size, with majority of the nonmerged systems lasting shorter than $10 \mathrm{~h}$.

[45] Statistical analysis of the DCS evolution shows that longer-lived DCSs are consistently larger with more extensive stratiform rain regions and anvil cloud shields. Composites of the maximum SR and $\mathrm{AC}$ area lag peak convective intensity (CI), where the lag increases linearly with system lifetime, and varies from $\sim 1 \mathrm{~h}$ for short-lived systems to more than $3 \mathrm{~h}$ for long-lived ones. For short to medium systems (lifetimes less than $6 \mathrm{~h}$ ), the lifetime is mainly attributed to the intensity of the initial convection. For systems that last longer than $6 \mathrm{~h}$ without merging with other systems, vigorous initial convection alone is not sufficient to explain their lifetime. These longer-lasting systems are associated with up to $50 \%$ higher midtropospheric relative humidity and up to $40 \%$ stronger middle to upper tropospheric wind shear. Such environments allow continuous growth of detrained hydrometeors by deposition after the initial intense convection, releasing latent heat in the process and supporting further development of SR and AC region. The increased staggered timing with lifetime between maximum SR/AC area and peak convective intensity indicates that changes in the overall diabatic heating structure associated with the transition from CC to SR and AC could help maintain the systems through generating mesoscale ascent, prolonging the system lifetime beyond $6 \mathrm{~h}$ by sustaining SR and AC development [Del Genio et al., 2012].

[46] Factors that are most relevant to the convective AC production were investigated and results show that the areal coverage of thick $\mathrm{AC}$ is strongly correlated with the size of $\mathrm{CC}$, updraft strength, and the SR area. After the initial intense convection in the developing stage, AC from detrainment of CC or remnants of SR precipitation continues spreading out with upper level wind. Stronger upper tropospheric wind speed and middle to upper tropospheric wind shear contribute directly to producing large areas of AC until systems mature. For example, the average wind speed (150 $\sim 200 \mathrm{mb}$ ) and wind shear (150 to $600 \mathrm{mb}$ ) for systems with AC radius $>120 \mathrm{~km}$ are $24 \%$ and $20 \%$ higher, respectively, than those with $\mathrm{AC}$ radius $=20 \mathrm{~km}$. When convection ceases and moisture supply to the $\mathrm{AC}$ region is cut off at the decaying stage, AC dissipates within a few hours. The influence of moisture on AC growth appears not directly through higher RH in the upper troposphere that favors growth of detrained ice, but rather indirectly through higher midtropospheric moisture, along with stronger deep layer shear that favor longer-lived and more intense DCSs, to produce larger size of convective AC.

[47] Analyses performed in this study provide a framework for comparison with long-term large-scale cloud resolving model (CRM) simulations to systematically evaluate their performance in simulating convections at various scales. Classification and automated cloud tracking can be applied on proxy observation data set from model output fields (e.g., simulated radar reflectivity and cloud top brightness temperature), allowing comparison of precipitation and cloud structure statistics directly with observations in the Lagrangian framework. The evolution of the CC/SR/ $\mathrm{AC}$, their lifetime and associated environments, and factors that impacts $\mathrm{AC}$ production found in this study should also be compared with more CRM simulated cases to diagnose the mechanisms responsible for transition from $\mathrm{CC}$ to $\mathrm{SR}$ and $\mathrm{AC}$, and provide guidance for parameterizing these processes in Global Climate Models. A recent field campaign conducted in Oklahoma (Midlatitude Continental Convective Clouds Experiment, or $\mathrm{MC}^{3} \mathrm{E}$, http://campaign. arm.gov/mc3e/ and http://mc3e.nsstc.nasa.gov/) incorporated high-resolution multiwavelength radar systems, surface and in situ aircraft measurements, and intensive atmospheric sounding observations. Data sets generated during $\mathrm{MC}^{3} \mathrm{E}$ have great potential for complementing the large-scale DCS morphology study performed in this paper through comprehensive comparison of the microphysical processes with CRM simulations.

[48] Acknowledgments. The authors thank Samson Hagos for his comments and suggestions. This research was primarily supported by the NOAA GOES-R project managed by Ingrid Guch and Mark DeMaria. The University of North Dakota authors were also supported by the DOE Atmospheric System Research (ASR) project under grant DE-SC0008468, the NASA CERES project under grant NNX10AI05G, and NASA EPSCoR CAN under grant NNX11AM15A. The PNNL authors were supported by the DOE ASR program. The NASA Langley authors were supported by both the CERES and ASR programs. 


\section{References}

Ackerman, T. P., K.-N. Liou, F. P. J. Valero, and L. Pfister (1988), Heating rates in tropical anvils, J. Atmos. Sci., 45(10), 1606-1623, doi:10.1175/ 1520-0469(1988)045<1606:HRITA $>2.0 . \mathrm{CO} ; 2$.

Bedka, K. M., and P. Minnis (2010), GOES 12 observations of convective storm variability and evolution during the Tropical Composition, Clouds and Climate Coupling Experiment field program, J. Geophys. Res., 115, D00J13, doi:10.1029/2009JD013227.

Carbone, R. E., J. D. Tuttle, D. A. Ahijevych, and S. B. Trier (2002), Inferences of predictability associated with warm season precipitation episodes, J. Atmos. Sci., 59(13), 2033-2056, doi:10.1175/1520-0469(2002) 059<2033:IOPAWW>2.0.CO;2.

Chen, S. S., and R. A. Houze (1997), Diurnal variation and life-cycle of deep convective systems over the tropical pacific warm pool, $Q$. J. $R$. Meteorol. Soc., 123(538), 357-388, doi:10.1002/qj.49712353806.

Cohen, A. E., M. C. Coniglio, S. F. Corfidi, and S. J. Corfidi (2007), Discrimination of mesoscale convective system environments using sounding observations, Weather Forecast., 22(5), 1045-1062, doi:10.1175/ WAF1040.1.

Coniglio, M. C., H. E. Brooks, S. J. Weiss, and S. F. Corfidi (2007), Forecasting the Maintenance of quasi-linear mesoscale convective systems, Weather Forecast., 22(3), 556-570, doi:10.1175/WAF1006.1.

Coniglio, M. C., J. Y. Hwang, and D. J. Stensrud (2010), Environmental factors in the upscale growth and longevity of MCSs derived from rapid update cycle analyses, Mon. Weather Rev., 138(9), 3514-3539, doi:10.1175/2010MWR3233.1.

Dai, A. (2006), Precipitation characteristics in eighteen coupled climate models, J. Clim., 19(18), 4605-4630, doi:10.1175/JCLI3884.1.

Del Genio, A. D., and W. Kovari (2002), Climatic properties of tropical precipitating convection under varying environmental conditions, J. Clim., 15(18), 2597-2615, doi:10.1175/1520-0442(2002)015<2597:CPOTPC $>2.0$. CO;2.

Del Genio, A. D., J. Wu, and Y. Chen (2012), Characteristics of mesoscale organization in WRF simulations of convection during TWP-ICE, $J$. Clim., 25(17), 5666-5688, doi:10.1175/JCLI-D-11-00422.1.

Feng, Z., X. Dong, B. Xi, C. Schumacher, P. Minnis, and M. Khaiyer (2011), Top-of-atmosphere radiation budget of convective core/stratiform rain and anvil clouds from deep convective systems, J. Geophys. Res., 116, D23202, doi:10.1029/2011JD016451.

Futyan, J. M., and A. D. Del Genio (2007), Deep convective system evolution over Africa and the tropical Atlantic, J. Clim., 20(20), 5041-5060, doi:10.1175/JCLI4297.1.

Garrett, T. J., et al. (2005), Evolution of a Florida cirrus anvil, J. Atmos. Sci., 62(7), 2352-2372, doi:10.1175/JAS3495.1.

Houze, R. A. (1989), Observed structure of mesoscale convective systems and implications for large-scale heating, Q. J. R. Meteorol. Soc., 115(487), 425-461, doi:10.1002/qj.49711548702.

Houze, R. A. (1993), Cloud Dynamics, 573 pp., Academic, San Diego, Calif.

Houze, R. A., B. F. Smull, and P. Dodge (1990), Mesoscale organization of springtime rainstorms in Oklahoma, Mon. Weather Rev., 118(3), 613-654, doi:10.1175/1520-0493(1990)118<0613:MOOSRI >2.0.CO;2.

Jensen, M. P., and A. D. Del Genio (2003), Radiative and microphysical characteristics of deep convective systems in the tropical western Pacific, J. Appl. Meteorol., 42(9), 1234-1254, doi:10.1175/1520-0450(2003) 042<1234:RAMCOD>2.0.CO;2.

Jirak, I. L., W. R. Cotton, and R. L. McAnelly (2003), Satellite and radar survey of mesoscale convective system development, Mon. Weather Rev., 131(10), 2428-2449, doi:10.1175/1520-0493(2003)131< 2428:SARSOM>2.0.CO;2.

Kane, R. J., C. R. Chelius, and J. M. Fritsch (1987), Precipitation characteristics of mesoscale convective weather systems, J. Clim. Appl. Meteorol., 26(10), 1345-1357, doi:10.1175/1520-0450(1987)026<1345:PCOMCW >2.0.CO;2.

Kennedy, A. D., X. Dong, B. Xi, S. Xie, Y. Zhang, and J. Chen (2011), A comparison of MERRA and NARR reanalyses with the DOE ARM SGP data, J. Clim., 24(17), 4541-4557, doi:10.1175/2011JCLI3978.1.

Kondo, Y., A. Higuchi, and K. Nakamura (2006), Small-scale cloud activity over the maritime continent and the western Pacific as revealed by satellite data, Mon. Weather Rev., 134(6), 1581-1599, doi:10.1175/ MWR3132.1.

Lang, S., W. K. Tao, J. Simpson, and B. Ferrier (2003), Modeling of convective-stratiform precipitation processes: Sensitivity to partitioning methods, J. Appl. Meteorol., 42(4), 505-527, doi:10.1175/1520-0450 (2003)042<0505:MOCSPP>2.0.CO;2.
Li, W., and C. Schumacher (2011), Thick anvils as viewed by the TRMM precipitation radar, J. Clim., 24(6), 1718-1735, doi:10.1175/ 2010JCLI3793.1

Lin, B., K.-M. Xu, P. Minnis, B. A. Wielicki, Y. Hu, L. Chambers, T.-F. Fan, and W. Sun (2007), Coincident occurrences of tropical individual cirrus clouds and deep convective systems derived from TRMM observations, Geophys. Res. Lett., 34, L14804, doi:10.1029/2007GL029768.

Machado, L. A. T., and H. Laurent (2004), The convective system area expansion over Amazonia and its relationships with convective system life duration and high-level wind divergence, Mon. Weather Rev., 132(3), 714-725, doi:10.1175/1520-0493(2004)132<0714:TCSAEO >2.0.CO;2.

Machado, L. A. T., and W. B. Rossow (1993), Structural characteristics and radiative properties of tropical cloud clusters, Mon. Weather Rev., 121(12), 3234-3260, doi:10.1175/1520-0493(1993)121<3234: SCARPO $>2.0 . \mathrm{CO} ; 2$.

Machado, L. A. T., W. B. Rossow, R. L. Guedes, and A. W. Walker (1998), Life cycle variations of mesoscale convective systems over the Americas, Mon. Weather Rev., 126(6), 1630-1654, doi:10.1175/1520-0493(1998) $126<1630$ :LCVOMC $>2.0$. CO;2.

Maddox, R. A. (1980), Meoscale convective complexes, Bull. Am. Meteorol. Soc., 61(11), 1374-1387, doi:10.1175/1520-0477(1980) 061<1374:MCC>2.0.CO;2.

McAnelly, R. L., and W. R. Cotton (1989), The precipitation life cycle of mesoscale convective complexes over the central United States, Mon. Weather Rev., 117(4), 784-808, doi:10.1175/1520-0493(1989) $117<0784:$ TPLCOM>2.0.CO;2.

Mesinger, F., et al. (2006), North American regional reanalysis, Bull. Am. Meteorol. Soc., 87(3), 343-360, doi:10.1175/BAMS-87-3-343.

Minnis, P., et al. (2008), Cloud detection in nonpolar regions for CERES using TRMM VIRS and Terra and Aqua MODIS data, IEEE Trans. Geosci. Remote Sens., 46(11), 3857-3884.

Minnis, P., et al. (2011), CERES edition-2 cloud property retrievals using TRMM VIRS and Terra and Aqua MODIS data-Part I: Algorithms, IEEE Trans. Geosci. Remote Sens., 49, 4374-4400.

Pope, M., C. Jakob, and M. J. Reeder (2008), Convective systems of the north Australian monsoon, J. Clim., 21(19), 5091-5112, doi:10.1175/ 2008JCLI2304.1.

Powell, S. W., R. A. Houze, A. Kumar, and S. A. McFarlane (2012), Comparison of simulated and observed continental tropical anvil clouds and their radiative heating profiles, J. Atmos. Sci., 69(9), 2662-2681, doi:10.1175/JAS-D-11-0251.1.

Rickenbach, T., P. Kucera, M. Gentry, L. Carey, A. Lare, R.-F. Lin, B. Demoz, and D. O. C. Starr (2008), The relationship between anvil clouds and convective cells: A case study in south Florida during CRYSTAL-FACE, Mon. Weather Rev., 136(10), 3917-3932, doi:10.1175/2008MWR2441.1.

Schumacher, C., and R. A. Houze (2003), Stratiform rain in the tropics as seen by the TRMM precipitation radar, J. Clim., 16(11), 1739-1756, doi:10.1175/1520-0442(2003)016<1739:SRITTA>2.0.CO;2.

Schumacher, C., R. A. Houze, and I. Kraucunas (2004), The tropical dynamical response to latent heating estimates derived from the TRMM precipitation radar, J. Atmos. Sci., 61(12), 1341-1358, doi:10.1175/ 1520-0469(2004)061<1341:TTDRTL>2.0.CO;2.

Steiner, M., R. A. Houze, and S. E. Yuter (1995), Climatological characterization of three-dimensional storm structure from operational radar and rain gauge data, J. Appl. Meteorol., 34(9), 1978-2007, doi:10.1175/ 1520-0450(1995)034<1978:CCOTDS $>2.0$. CO;2.

Varble, A., A. M. Fridlind, E. J. Zipser, A. S. Ackerman, J.-P. Chaboureau, J. Fan, A. Hill, S. A. McFarlane, J.-P. Pinty, and B. Shipway (2011), Evaluation of cloud-resolving model intercomparison simulations using TWP-ICE observations: Precipitation and cloud structure, J. Geophys. Res., 116, D12206, doi:10.1029/2010JD015180.

Williams, M., and R. A. Houze (1987), Satellite-observed characteristics of winter monsoon cloud clusters, Mon. Weather Rev., 115(2), 505-519, doi:10.1175/1520-0493(1987)115<0505:SOCOWM>2.0.CO;2.

Zhang, J., et al. (2011), National Mosaic and Multi-sensor QPE (NMQ) system: Description, results, and future plans, Bull. Am. Meteorol. Soc., 92(10), 1321-1338, doi:10.1175/2011BAMS-D-11-00047.1.

Zipser, E. J., and K. R. Lutz (1994), The vertical profile of radar reflectivity of convective cells: A strong indicator of storm intensity and lightning probability?, Mon. Weather Rev., 122(8), 1751-1759, doi:10.1175/ 1520-0493(1994)122<1751:TVPORR>2.0.CO;2.

Zipser, E. J., C. Liu, D. J. Cecil, S. W. Nesbitt, and D. P. Yorty (2006), Where are the most intense thunderstorms on Earth?, Bull. Am. Meteorol. Soc., 87(8), 1057-1071, doi:10.1175/BAMS-87-8-1057. 